\title{
Educational Technology and Teacher-Student Technology Competency: a Pathway to Teaching English with Technology
}

\author{
Ismail Anas \\ State Polytechnic of Ujung Pandang \\ ismailanas@poliupg.ac.id
}

\begin{abstract}
This article presents a pathway to teaching English with technology which focuses on the elaboration of three essential approaches; they are 1) the technology tools (TT), 2) the teacher technology competency (TTC), and 3) the student technology competency (STC). Although EFL teachers have wide access to the high-end technology tools, however, their application in instruction will not be successful without being supported by the teacher professional use and student acceptance of the technology. Preparing the EFL teachers for teaching English with technology requires a continuing evaluation regarding the readiness of the technology tools, TTC, and STC. These three approaches should be taken into account seriously to transform TEFL into technology in instruction. The implications for research, teachers, students, practice, curriculum developers, and EFL teacher educator will also be discussed.
\end{abstract}

Keywords: Technology tools, teacher-student technology competency, technology in instruction, ELT 


\section{Ismail Anas}

\section{INTRODUCTION}

The advances in technology have brought significant changes to the way people interact, teach and learn. There have many studies reported in the literature emphasizing the effectiveness and efficiency use of technology in language learning (ex. Brooks-young, 2007; Salaberry, 2001). Empirically, the government spent a lot of money for considerable investment in all levels of educational sectors to provide a technological infrastructure to support teaching and learning while a very little attention to professional development activities and scholarly approaches among the educational practitioners (Kirkwood \& Price, 2013).

In the Indonesian context of EFL teaching, a huge demand for English language curriculum at many levels of education in Indonesia requires the EFL teachers to be able to transform TEFL into a digital world. However, the application of technology in instruction seems to be a daunting task for most EFL teachers as well as the student readiness to accept technology. Therefore, it is necessary to have a look at the empirical and practical gaps that hamper the EFL teachers from the actual use of educational technology in ELT. In this digital era, it is not only the classroom-based technology in instruction should be wellunderstood by the EFL teachers, but also the rise of web-based technology as the emerging platform in most EFL teaching context around the world. The advances in technology are changing over time, so the EFL teacher digital literacy, technology competency, and internet literacy are no longer the optional skills to survive in this digitalized era. In the other hand, the student's digital literacy grow very fast in which they are actively engaged in digital technology devices (Android-based smartphone, tablet, iPad) as well as web-based platforms (social media, weblog, e-learning, video-streaming sites, etc.). Based on the UNESCO ICT Competency Framework for the teacher, there are three essential approaches to teaching successfully, they are 1) technology literacy, 2) knowledge deepening, and 3) knowledge creation (Unesco, 2008, 2011).

The objective of this article is to shed light on how EFL teachers should be empowered and equipped with technology-related skills to be able to integrate ICT into instruction. It focuses on three essential approaches to preparing the EFL teachers ready to uptake technology both in the classroom and web-based instruction; they are 1) the availability of technology tools, 2) teacher readiness to use technology in instruction, and 3) the student readiness to accept technology. These three approaches, however, are closely interrelated as the key indicators of successful teaching English with technology.

\section{ESSENTIAL APPROACHES TO TEACHING ENGLISH WITH TECHNOLOGY}

As technology and its integration in the educational sector gained more popularity and attention from the teachers and educational practitioners worldwide, it is necessary to have a look at the essential approaches to using technology effectively and successfully. Informed by research, personal experience, recent works and latest studies in the literature, this section elaborates the three interrelated approaches as shown in figure 1. 


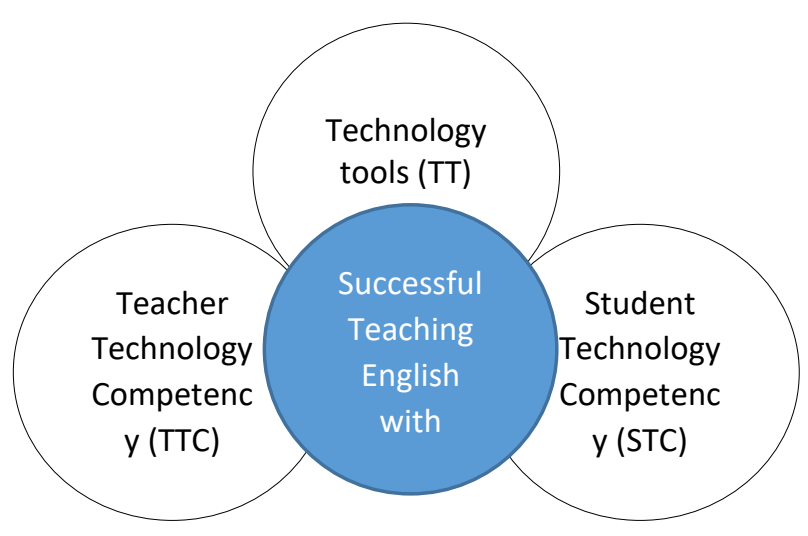

\section{Figure 1. The framework of approaches to teaching English with technology}

The first approach to teaching English with technology is the availability and accessibility of technology tools for use in teaching and learning environment. It is necessary to ensure that EFL teachers and students have access to the provision of technology tools. In Indonesian higher education context, some institutions have made a great investment in providing access to technology equipment such as classroom-based and web-based technologies. The classroom-based technologies include LCD projector, screen banner display, internet network infrastructure, language lab, computer, laptop, printing/ scanning/ copying tools, portable devices such as recording tools, and digital camera/video recorder. Besides that, the web-based technologies include e-learning platforms, academic information system, website, and cloud-based repository. In this context, there are two crucial issues that EFL teacher should take it into account; they are 1) the availability of technology tools and 2) the accessibility of technology tools. Regarding the availability issue, although some institutions have provided such technologies, they might be having difficulties in providing equal service to all staffs. About the accessibility issue, not all EFL teachers have ease of access to technology tools even though in their home institutions. In relation to these issues, the home institution might want to have a look at the provisioning of the center for technology in self-access (Reinders \& Lázaro, 2007). Each institution might have different approaches and strategies to making use of technology in context.

The second approach is the teacher technology competency (TTC) that fosters the teacher's ability to incorporate and integrate technology into instruction. It is not only the teacher's ability to use particular technology tool or device but also they will need to have a good pedagogical content knowledge to make use of technology in instruction- and it is socalled technological pedagogical content knowledge (TPCK) (Mishra \& Koehler, 2006). In Addition to this, a language teacher should have knowledge and technology-related skills for his/her professional teaching purposes. They are expected to meet the technology standard for language teachers. They are expected to be able to 1) demonstrate their knowledge and skills in basic technological concepts and operational competence, 2) demonstrate their understanding of a wide range of technology supports for language learning and options for using them in a given setting, and 3) actively strive to improve their skills and knowledge base to evaluate, adopt, and adapt emerging technologies throughout their professional careers (Healey et al., 2008). A quiet similar to this, Teacher Technology Competency 


\section{Ismail Anas}

Committee (1998) had developed the teacher technology competency standard that emphasized on four domains, they are 1) basic technology operation, 2) personal/ professional use of technology tools, 3) social, ethical, and human issues, and 4) application of technology in instruction. In fact, the condition of Indonesian EFL teachers is still far beyond the standard meaning that before requiring them to transform technology into instruction, they will need to improve their TPCK. For example, an auto-ethnographical study on the implementation of Moodle-based in learning in ELT suggests that intensive training on TTC should be done earlier in pre-service teacher education (Anas, 2015). Inservice EFL teachers might not have enough time to participate in an educational technology application short course. The lack of TTC might bring negative impact on the teacher's reluctance of using technology in their classes.

The third approach is the student technology competency (STC) that fosters the student's ability to accept technology as a medium of language learning instruction. It is important to understand the factors affecting the student's behavior in the way they can accept technology integration in the language learning environment (Ifenthaler \& Schweinbenz, 2016). For example, a teacher might want to use e-learning platform as a medium of online learning instruction. However, it is necessary for the teacher to ensure that the students are already familiar with the platform and be able to use it. The teacher should make a self-questioning before deciding to use a particular technology in the classroom. For instance, before teaching a particular subject or targeted language using technology, a teacher should necessarily ask an initial self-questioning such as what are the goals and objectives of the lesson? Which technology tool is available? Which one I am familiar with, and so are my students? What kind of technology instruction that might work? Do I need ICT specialist assistance? etc. By doing this, a teacher can figure out what technological and pedagogical approaches should be integrated to achieve the teaching goals and objectives.

The EFL teachers are expected to be able to integrate the three approaches above to avoid chaos in teaching and learning practice using technology. If one of the three approaches is ignored or not well-understood by the EFL teachers, they will possibly fail their student's learning and engagement. The institutions should provide the teachers and students with wide access to adequate technology tools to support teaching and learning activities. The teachers should develop their technology competency as well as their TPCK. They also need to have a quick adaptation to a rich technology environment as well as to identify their student's preferences in learning English with technology. The learners should meet the student technology competency standard (STC), so they can easily adapt to the technology-based and the digitally rich learning environment (see TESOL, 2008).

\section{FOSTERING THE IMPORTANCE OF TECHNOLOGY IN ELT}

The emerging needs in today's English teaching profession might fall within the area of innovations in continuing professional development for English language teacher educators and teachers (see Pickering \& Gunashekar, 2015 p.13). The EFL teachers today are now living in a digitally rich technology environment both in the home and in school. At the same time, students are also actively engaged in digital communication and learning platform which affect the way they interact, communicate and learn. They are now coming 
to school with high-end digital devices such as touch-screen laptop, Android-based smartphone, portable Wi-Fi (internet modem), tablet, and iPad. On the contrary, most senior in-service EFL teachers are not digital natives so that we might find the students more digitally literate than the teachers. That is why the application technology in language learning instruction should be taken into account. Both the EFL teacher and the student are highly dependable on the use of technology in the language learning environment. Some empirical studies have been recently reported in the literature on how web-based technologies made changes to the modes of learning interactions. For example, the use of Facebook in language learning (Ian \& Ty, 2013; Kabilan, Ahmad, \& Abidin, 2010), elearning in language teaching (Anas, 2015; Chinnery, 2008; Gluchmanova, 2015).

The rise of social media Facebook as a medium of language instruction has gained more popularity over the decades (Dare \& Sir Gar, 2011). Although it was designed for a social communication platform, it provides telecollaboration functionalities for users such as closed group, online chat, file sharing, video chat, and useful links sharing. Getting EFL teachers and the students to Facebook offers flexibility in learning communication. Learning is a social and academic activity which can be merged as a socio-academic virtual environment on Facebook (Wang, Lin, Yu, \& Wu, 2013). In Indonesian context of the student's communication behavior, they are likely to spend many hours on the internet as well as on Facebook, so the teachers might find it easier to communicate with their students wherever they are as long as they are connected to the internet. Many EFL teachers decided to use Facebook as a medium of language instruction such as handling an online discussion via Facebook group or group conversation feature. There are benefits of using Facebook in ELT such as learning flexibility, intense communication with the students, task submission, speaking practice via video chat, teaching writing, group discussion, integrated online quiz and testing (facebook + google-form), etc. Facebook is one of the examples of web-based technologies that EFL teachers can explore and utilize so that EFL teachers can decide whether to Facebook or not to Facebook.

\section{TTC VS. STC; DOES IT MATTER?}

Teacher Technology Competence (TTC) has a pivotal role in the transformation of TEFL into a digitally rich technology environment. The EFL teachers should have the ability to design, apply, develop, assess the curriculum and instruction with technology, and socalled teacher technological pedagogical content knowledge (TPCK) (Niess, 2011). Does TPCK matter? This TPCK had been outlined by Mishra et al. (2013) emphasizing on the TPCK framework for teachers and teacher educators. They argue that ICT integration should be visualized by the teachers. They also argue that the teachers should be able to transform technology into a variety of technology integrations in existing practice both pedagogy and content domains. However, the TPCK framework only focuses on the teacher technology competency and pedagogical content knowledge (PCK), but a very little attention to the student technological knowledge in which it creates practical gaps in its implementation.

This section sheds light on the empirical and practical gaps between the TTC and STC. There is an emerging issue hampering the implementation of technology-enhanced teaching and learning called student acceptance towards technology. Although there have been many studies reported in the literature regarding technological acceptability, many teachers still 


\section{Ismail Anas}

disregard the importance of this issue as a perennial factor affecting the incorporation of technology into practice. According to Davis at al (1989) there are two factors affecting the EFL student acceptance of technology in CALL, they are 1) perceived ease of use, and 2) perceived usefulness. It can be implied that teachers cannot just select a particular technology to be used in their teaching without knowing the student perceived ease of use and usefulness of the technology. Therefore, one strategy that EFL teacher can do is negotiating the kinds of technology tools and instructions before the application. By doing this, The EFL teachers will have a clear picture of what strategies and instructions to make use of the technology.

\section{NEEDS AND EXPECTATIONS OF TECHNOLOGY-LITERATE EFL TEACHER}

Firstly, it is necessary to have a closer look at the pre-service EFL teacher educations as well as the teacher training centers. This initial phase is the start point of the EFL teachers educated and trained to work further in many levels of educational institutions. Regarding the technological aspect of teaching and learning, an adequate portion of ICT courses should be there in the curriculum. Unfortunately, not all English language curriculum in the preservice teacher education meet the demands of the current digitally rich learning environment. A recent study reported in Nordin at al. (2013) argues that pre-service teachers in New Zealand have a high rating in their content knowledge (CK), but show a low rating in technological knowledge (TK). Similarly to a study conducted in Australia about ICT and teacher education for beginning and experienced teachers, Pearson (2003) argue that although the adoption of a range of approaches had been implemented, the evaluation of some specific approaches was still necessary.

In Indonesia, the rise of the technologically rich environment in many levels of education has become a serious issue in teaching implementation. Workshops on ICT, web-based technology, and Internet-based materials have gained popularity amongst the universities, teacher training centers for ICT, and the private sector of educational services. These initiatives would not probably work properly without the adequate input of basic technology operation that hampers the actual use of the ICT. Otherwise, although providing some ICT training for the teachers, it would be less effective while they have serious problems in technology input, especially for the senior EFL teachers. This paper would not likely claim that intensive ICT training is useless, but it is important to have a look at the provision of the technological input as a basic foundation for the teachers to successfully accept the technology, then the training might work effectively.

TT, TTC, and STC do matter in ELT as key indicators of transforming TEFL into today's fully digital world. The EFL teachers can now develop a more interactive learning using technology such as e-collaboration, online tutorial, web-based teaching (Ex. elearning, MOOCs, webinars, etc.). Most of the EFL teachers are not digital natives while the students are mostly digital natives (except in isolated area) meaning that most of the teachers were not born in the digital era, so they were essentially actively engaged in technology during their education. On the contrary, the students nowadays are mostly digital natives in which they were already introduced to technology in their early education. It is assumed that 
they will likely be more familiar with and be faster learning and accepting the technology than the teachers.

The needs and expectation of the technology-literate EFL teachers will likely be the following criteria:

1. Receiving an adequate input of basic technological application, personal/professional use of technology, social/ethical knowledge of using technology, and application of technology in instruction (see Teacher Technology Competency Committee, 1998; Unesco, 2008)

2. Having an adequate technological knowledge (TK), pedagogical knowledge (PK), and content knowledge (CK), and so-called TPCK (see Koehler et al., 2013; Mishra \& Koehler, 2006, 2008)

3. Being able to foster the students' acceptance of technology to figure out what technology the students are familiar with and interested in.

4. Being able to evaluate the application of the technology to make use of it successfully.

\section{IMPLICATIONS FOR ELT}

The implementation of the three approaches to teaching English with technology provides some implications for the research, practice, teachers, students, and educational policy makers as follows:

\subsection{Research practice}

The implications for the research practice are likely to be providing EFL researchers for organizing and synthesizing their research goals and objectives. The three approaches will guide them to find out the gaps such as theoretical gaps, empirical gaps, and practical gaps that hamper the EFL teachers from the actual use of technology in ELT. They will also be able to find out the urgent area of investigation to which the technology can effectively work in teaching. For example, a practical gap was identified in the use of social media platform in ELT in which the teachers might find some distractions (ex. Uncontrollable discussion, irrelevant posts with the topic, hyperconnectivity, willingness to use social media, etc.) during their online interaction with the student. Therefore, they can set up an action research to overcome such distractions (see Cheong, Shuter, \& Suwinyattichaiporn, 2016).

\subsection{English language teaching practice}

Teaching in a technologically rich environment might be a daunting task for most EFL teachers. In supporting the use of technology in EFL instruction, the approaches shed light on how teaching English with technology should be fostered and well-managed. English language teaching (ELT) in Indonesia faces some challenges regarding the application of technology in instruction. With this in mind, the teacher educators, EFL teachers, and the students can collaborate to overcome the emerging issues in teaching English with technology. Given the importance of encouraging the EFL teachers to teach English using technology, it is necessary for every scholar in the field to contribute to the development of ELT approaches especially in a digital world. 


\section{Ismail Anas}

\subsection{Teacher}

The EFL teachers as active learning agents hold a great responsibility to deliver quality teaching for their students. Teachers who have good TPCK will find it easier to transform technology into instruction. They will not only learn how to use technological tools but also be able to demonstrate their ability to use them for their teaching purposes. With this in mind, the teacher educator both in pre-service and in-service teacher education will keep enriching the teachers with intensive technological input so they can easily adopt the ICT as a medium of instruction in their classes. Having also the institution provide adequate technological tools to support the teaching and learning process, they will get the ease of access to such tools as an effort to remove barriers regarding the availability of educational technology.

\subsection{Student}

In the past, students were seen as passive agents of learning while today the EFL teacher should see them as active agents in the learning process. By understanding the principles of the $21^{\text {st }}$-century teaching perspective, teachers can involve them in the process of learning such as material development, student-created videos, teacher-student collaborative learning, etc. With the provision of EFL technology-literate teachers, it will have a significant impact on student learning both in improving their receptive and productive skills. Having both teacher and student perform in a digitally rich environment such as working with e-learning, online tutorial, online testing, Facebook-mediated learning, and participating in MOOCs will no longer be a dream. The teachers just need to keep engaging their students in learning with technology by actively giving them a rich input of technology-enhanced learning.

\subsection{Curriculum developers}

The curriculum is the starting point of the teaching pathways covering the dynamic aspects of learning to guide the teachers to stay on track and well-directed. The curriculum developers will need feedbacks from practitioners, teaching industries, educational stakeholders as well as the students to formulate a well-designed curriculum that meets the learning needs and expectations. They will also need a well-informed analysis obtained from scholarly works, teaching experiences, best practices, empirical gaps as well as the practical gaps to help them formulate the curriculum goals and objectives. For example, the English language curriculum in a pre-service teacher education offers a little portion of ICT-based courses which affects the students' technological input of how the technology works effectively in ELT. The curriculum developers might find a practical gap in the field in which the portion of the ICT-based courses should be added.

\subsection{EFL teacher educator}

EFL teacher educators are responsible for providing practical training on the emerging issues in the field that hampers the implementation of technology-based teaching in ELT. They will need feedbacks from the ELT practitioners, EFL teachers, and students to provide specific training for the teachers. For example, an emerging issue on the use of e-learning 
implementation experienced by the EFL teachers in which the students face some difficulties regarding the ease of use and access to the platform. The teacher should evaluate the factors affecting the student perceived ease of use and access faced by the students. As a response to this issue, the teacher or the teacher educator should work on it to resolve the problems. The approaches presented in this paper will help and guide the teacher educators to design and develop specific professional development programs for EFL teachers. The teachers and the teacher educators can build synergy and collaboration to investigate the problems encountered in the field of ELT and work together to find out better approach and strategy to get the problems solved.

\section{CONCLUSION}

Preparing the EFL teachers for teaching English with technology still requires a continuing evaluation regarding the readiness of the technology tools, TTC, and STC. These three approaches should be taken into account seriously to transform TEFL into technology in instruction. The educational policy makers, curriculum developers, EFL teacher educators, EFL teachers, students, stakeholders, and ICT specialists should sit together and make a collaboration to resolve the emerging issues in the area of teaching English with technology. It is necessary to integrate the three approaches mentioned above to foster the needs and expectations of the current digitally rich learning environment. Firstly, the institutions should make a great investment in the technological infrastructure that paves the way to provide ease of use and access to technology. Secondly, the teacher educator should be working on the EFL teacher pedagogical content knowledge (TPCK) as well as providing intensive technological input for the teachers. Thirdly, the EFL teachers should take into account investigating the students' preferences and acceptance of the technology. Also, curriculum developers should revisit the current curriculum regarding the application of technology in instruction.

\section{REFERENCES}

Anas, I. (2015). Utilizing a Moodle-Based E-Learning Platform in ELT: An Autoethnography. In 4th ELTLT International Conference (pp. 372-388). Faculty of Languages \& Arts, State University of Semarang.

Brooks-young, S. (2007). Digital Age Literacy for Teachers: Applying Technology Standards to Everyday Practice. Washington, D.C: ISTE Publications.

Cheong, P. H., Shuter, R., \& Suwinyattichaiporn, T. (2016). Managing student digital distractions and hyperconnectivity: communication strategies and challenges for professorial authority. Communication Education, 65(3), 272-289. https://doi.org/10.1080/03634523.2016.1159317

Chinnery, G. M. (2008). e-Language Learning and Teaching. CALICO Journal, 25(3), 471481. https://doi.org/10.1017/S0261444800007011

Dare, L., \& Sir Gar, C. (2011). Facebook: Training Modules. Stutgart:Germany: MFG:Innovation Agency for ICT and Media. Retrieved from http://www.sveaproject.eu/fileadmin/_svea/downloads/Video_Sharing_01.pdf

Davis, F. D., Bagozzi, R. P., \& Warshaw, P. R. (1989). User acceptance of computer 
Ismail Anas

technology : a comparison of two theoretical models. Management Science, 35(8), 9821003.

Gluchmanova, M. (2015). Application of e-Learning in Foreign Language Teaching at the Technical University. Procedia - Social and Behavioral Sciences, 174, 3144-3149. https://doi.org/10.1016/j.sbspro.2015.01.1053

Healey, D., Hegelheimer, V., Hubbard, P., Ioannou, S., Kessler, G., \& Ware, P. (2008). TESOL Technology Standards Framework. Virginia, USA: Teachers of English to Speakers of Other Languages, Inc. (TESOL). Retrieved from https://www.tesol.org/docs/books/bk_technologystandards_framework_721.pdf

Ian, F., \& Ty, G. (2013). Facebook Guide for Educators: A Tool for Teaching and Learning. New Zealand: The Education Foundation HQ.

Ifenthaler, D., \& Schweinbenz, V. (2016). Students' Acceptance of Tablet PCs in the Classroom. Journal of Research on Technology in Education, 48(4), 306-321. https://doi.org/10.1080/15391523.2016.1215172

Kabilan, M. K., Ahmad, N., \& Abidin, M. J. Z. (2010). Facebook: An online environment for learning of English in institutions of higher education? The Internet and Higher Education. https://doi.org/10.1016/j.iheduc.2010.07.003

Kirkwood, A., \& Price, L. (2013). Missing : evidence of a scholarly approach to teaching and learning with technology in higher education. Teaching in Higher Education, 18(3), 327-337. https://doi.org/10.1080/13562517.2013.773419

Koehler, M. J., Mishra, P., Akcaoglu, M., \& Rosenberg, J. M. (2013). The technological pedagogical content knowledge framework for teachers and teacher educators. ICT Integrated Teacher Education: A Resource Book.

Mishra, P., \& Koehler, M. J. (2006). Technological pedagogical content knowledge: a framework for teacher knowledge. Teachers College Record, 108(6), 1017-1054. https://doi.org/10.1111/j.1467-9620.2006.00684.x

Mishra, P., \& Koehler, M. J. (2008). Introducing technological pedagogical content knowledge. $\quad$ Retrieved from http://punya.educ.msu.edu/presentations/AERA2008/MishraKoehler_AERA2008.pdf

Niess, M. L. (2011). Investigating TPACK: Knowledge Growth in Teaching with Technology. Journal of Educational Computing Research, 44(3), 299-317. https://doi.org/10.2190/EC.44.3.c

Nordin, H., Davis, N., \& Ariffin, T. F. T. (2013). A Case Study of Secondary Pre-service Teachers' Technological Pedagogical and Content Knowledge Mastery Level. Procedia - Social and Behavioral Sciences, 103, 1-9. https://doi.org/10.1016/j.sbspro.2013.10.300

Pearson, J. (2003). Information and Communications Technologies and Teacher Education in Australia. Technology, Pedagogy and Education, 12(1), 39-58. https://doi.org/10.1080/14759390300200145

Pickering, G., \& Gunashekar, P. (2015). Innovation in English Language Teacher Education. Innovation in English Language Teacher Education. Retrieved from http://www.britishcouncil.in/sites/britishcouncil.in2/files/tec14_papers_final_online.pdf \#page $=275$ 
Reinders, H., \& Lázaro, N. (2007). Innovation in language support: the provision of technology in self-access. Computer Assisted Language Learning, 20(2), 117-130. https://doi.org/10.1080/09588220701331428

Salaberry, M. R. (2001). The Use of Technology for Second Language Learning and Teaching: A Retrospective. The Modern Language Journal, 85(1), 39-56. https://doi.org/10.1111/0026-7902.00096

Teacher Technology Competency Commitee. (1998). Teacher Technology Competencies. Teacher Technology Competency Committee. Retrieved from http://www.edb.utexas.edu/education/assets/files/ltc/about/TTCompetencies.pdf

Unesco. (2008). ICT Competency Standards for Teachers: Competency Standards Modules. The United Nations Educational, Scientific and Cultural Organization. Retrieved from http://cst.unesco-ci.org/sites/projects/cst/The Standards/ICT-CST-Competency Standards Modules.pdf

Unesco. (2011). Unesco ICT competency framework for teachers. France.

Wang, J., Lin, C. F. C., Yu, W. C. W., \& Wu, E. (2013). Meaningful engagement in facebook learning environments: Merging social and academic lives. Turkish Online Journal of Distance Education, 14(1), 302-322. 